Постижение студентами-иностранцами

особенностей менталитета русского народа

на примере авторского стиля А. И. Солженицына

(продвинутый уровень владения русским языком)

\author{
Гончарова Н. А., Швецова В. М.
}

\begin{abstract}
Аннотация. Цель исследования - разработать на основе лингвистического анализа текстов А. И. Солженицына приёмы обучения студентов-иностранцев особенностям менталитета русского народа на материале «восстановленных» лексем, присутствующих в «живых» текстах писателя. В настоящей статье подчеркивается значимость использования созданных носителями языка «живых» текстов в процессе обучения студентов-иностранцев русскому языку не только с целью правильного фонетического, лексического и грамматического оформления высказываний на русском языке, но и с целью наглядного постижения ментальных особенностей русскоговорящих людей, что способствует преодолению «культурного шока» обучающимися. Научная новизна исследования заключается в разработке авторских приемов обучения студентов-иностранцев осознанию и интерпретации «восстановленных» лексем писателя с учётом контекстного употребления языковых единиц в текстах произведений. В результате лингвистического анализа авторского стиля А. И. Солженицына разработаны авторские приемы обучения студентов-иностранцев русскому языку на продвинутом уровне, позволяющем обучающимся не только читать и понимать тексты классической литературы, созданные носителями языка, но и при помощи лексического («восстановленные» лексемы) оформления высказываний осознавать и интерпретировать ментальные особенности русского народа.
\end{abstract}

\title{
Familiarizing Foreign Students with Specificity of the Russian Mentality by the Example of A. I. Solzhenitsyn's Works (Advanced Level of the Russian Language Proficiency)
}

\author{
Goncharova N. A., Shvetsova V. M.
}

\begin{abstract}
The research objective is as follows: to develop methodological techniques to familiarize foreign students with specificity of the Russian mentality by the example of "revived" lexemes identified in A. I. Solzhenitsyn's "living texts". The research methodology includes a linguistic analysis of A. I. Solzhenitsyn's works. The researchers emphasize importance of using "living texts" created by native speakers when teaching the Russian language to foreign students; the use of "living texts" promotes formation of students' Russian-language competence, helps them to understand specificity of the Russian mentality and to overcome a "cultural shock". Scientific originality of the study lies in the fact that the researchers propose their original techniques to familiarize foreign students with Solzhenitsyn's "revived" words taking into account their contextual usage. The research findings are as follows: relying on a linguistic analysis of A. I. Solzhenitsyn's individual style, the authors develop their original methodology to teach Russian as a foreign language at the advanced stage. Advanced level students' language competence allows them to read the Russian classical literature and, what's more, to understand specificity of the Russian mentality manifested in "revived" words.
\end{abstract}

\section{Введение}

Актуальность исследования обусловлена тем, что в условиях мобильности обучающихся по всему миру возникла необходимость не только в овладении языком международного общения - в настоящее время английским, - но и в овладении языком той страны, в которой готов обучаться студент-иностранец. Современная 
Россия принимает для обучения студентов из разных стран, воспитанных в разных религиозных и культурных традициях, имеющих разные восприятия аналогичных явлений действительности. Несомненно, изучение студентами-иностранцами русского языка не является легкодостижимой целью, поскольку русский язык принадлежит к одному из сложнейших языков мира. Так, чтобы правильно, грамотно и красиво изъясняться на русском языке, студенту-иностранцу необходимо постичь тонкости орфоэпической природы, специфику репрезентации лексических единиц, сложную грамматическую организацию языкового строя, множество исключений на всех языковых уровнях, специфику организации спонтанной речи - все то, что делает общение студента-иностранца с истинными носителями языка и культуры доступным и понятным [10].

Естественно, что владение студентом-иностранцем русским языком может предполагать разные уровни: от базового до продвинутого [20]. Современное образование предъявляет высокие требования к уровню владения тем языком, на котором будет обучаться студент-иностранец. Следовательно, языковая подготовка обучающегося должна стремиться к продвинутому уровню владения языком, что позволит данному студенту понимать преподаваемые на русском языке учебные предметы, спонтанно общаться с носителями языка. Однако зачастую, попадая в естественную языковую среду, студент-иностранец, даже имея высокий уровень владения языком принимающей его страны, не может адекватно понять речь носителей языка, не в состоянии правильно реагировать на высказывания, не в силах осознать особенности поведения и менталитета носителей языка [24]. Данный факт принято называть «культурным шоком». И справедливо звучит мнение о том, что «обучение языку и культуре необходимо объединить. Результаты исследования по культурным факторам должны быть показаны в способности овладения целевым языком и культурой для обучающихся через промежуточное звено обучения русскому языку» [16, с. 65]. В данной связи вопрос о значимости осмысления ментальной специфики восприятия реалий окружающей действительности русским народом и приемах обучения студентов-иностранцев особенностям менталитета, заданным русским языком, представляет интерес для теоретиков образования, педагогов-практиков, методистов [6; 13; 17].

Необходимость разработки приемов обучения студентов-иностранцев русскому языку на продвинутом уровне, предполагающем постижение особенностей менталитета русского народа, позволила нам решить следующие задачи:

- во-первых, провести лингвистический анализ «живых» текстов А. И. Солженицына для выявления «восстановленных» лексем, в наибольшей мере отражающих особенности менталитета русского народа;

- $\quad$ во-вторых, предложить примеры приемов обучения, направленных на осознание и интерпретацию студентами-иностранцами «восстановленных» лексем с учетом авторского употребления данных лексем в «живых» текстах для преодоления обучающимися «культурного шока» и наглядного постижения не только фонетических, лексических, грамматических особенностей русского языка на продвинутом уровне, но и для понимания специфики менталитета русского народа.

Разработка авторских приемов обучения студентов-иностранцев особенностям менталитета русского народа позволила обратиться к следующим методам исследования: методу анализа научных исследований, методу лингвистического анализа, сравнительно-сопоставительному методу, методу контент-анализа, дескриптивному методу.

Теоретической базой исследования послужили труды А. А. Брагиной, А. Г. Лыкова и др., в которых анализируются условия и особенности текстовой реализации слов в языковой картине мира русского народа; работы Е. В. Дишкант, Л. С. Крючковой, Н. В. Мощинской, Г. В. Кретининой, А. А. Поздняковой, Ц. Лю и др., затрагивающие лингводидактические аспекты обучения языкам.

Практическая значимость исследования заключается в том, что представленные авторские приемы обучения студентов-иностранцев русскому языку на продвинутом уровне могут быть использованы в практике работы со студентами-иностранцами в ходе подготовки студентов к осуществлению коммуникации на русском языке не только с учетом правильного употребления фонетических, лексических, грамматических особенностей русского языка, но и с учетом понимания и осознания специфики менталитета русского народа.

\section{Теоретический аспект исследования}

В современной методике преподавания языков акцентируется внимание на обучение языку не только как средству общения, познания мира, но и как средству приобщения к национальной культуре народа, как к средству постижения особенностей менталитета носителей языка [12; 27]. Мы уверены, что владение студентами-иностранцами русским языком на продвинутом уровне предполагает не только безупречное знание фонетических, лексических, грамматических особенностей русского языка, но и понимание особенностей менталитета русского народа. Естественно предположить, что наиболее оптимальным средством постижения особенностей менталитета носителей языка студентами-иностранцами являются тексты классической литературы, созданные носителями языка, т.е. «живые» тексты, в которых наглядно при помощи лексического и грамматического оформления высказываний переданы ментальные особенности русского человека. Именно в таких «живых» текстах с наибольшей полнотой проявляются характерные особенности употребления антонимичных и синонимичных оборотов, специфика и поэтапность концептуализации языковой действительности в сознании носителей языка [5], особенности постижения индивидуумом текстовой 
семантики [28-30], тонкости менталитета русского народа в целом, отраженные в развитии языковых единиц русского языка в частности, и т.д.

Факт развития единиц русского языка лингвисты связывают с появлением новых языковых единиц неологизмов, а точнее - заимствований $[2 ; 3 ; 15]$ и окказионализмов $[1 ; 14 ; 26]$, приводящих к количественному увеличению лексического запаса любого естественного языка. Методисты соотносят познание неологизмов и окказионализмов студентами-иностранцами не только с обогащением активного и пассивного лексического запаса, но и с познанием менталитета русского народа [9].

В «живых» текстах классической литературы, созданных носителями языка, присутствуют неологизмы, окказионализмы, «восстановленные» единицы, которые отражают не только момент постоянного пополнения новой лексикой системы русского языка, но и соотносятся с составными частями индивидуальноавторских конструкций, являющихся результатом серьезной лингвистической работы мастера художественного слова или любого носителя языка. Зачастую в системе окказиональных новообразований исследователями не различаются слова авторского происхождения и слова, не имеющие авторства; не дифференцируются неологизмы, в результате чего данный пласт лексики относится к «восстановленным» лексемам, которые определяются как слова, накопленные и незаслуженно забытые, но с течением времени восстановленные и востребованные языком (рубезок, частоговорка, застыдчивость, раззарчивый, табуниться, впробежь и др.). Именно такие единицы в изобилии присутствуют в текстах А. И. Солженицына.

Попутно заметим, что выбор произведений именно данного автора с целью разработки приемов, направленных на постижение студентами-иностранцами менталитета русского народа, объясняется тем, что сам писатель неоднократно подчеркивал мысль о том, что в развитии русского литературного языка, отражающего менталитет нации, особая роль принадлежит единицам авторского (писательского) происхождения. Именно в подобных единицах мастер слова видит оптимально значимую перспективу для дальнейшего становления языка и выражения особенностей русского менталитета. Мастерство писателя позволяет реализовать в своем языковом сознании такую лексему, семантика которой «сфокусирует» уже существующее, зафиксированное в словарях содержание, в наибольшей мере раскроет культурные особенности и особенности менталитета русской нации.

Для преподавателя русского языка как иностранного трудность подбора «восстановленных» лексем в произведениях А. И. Солженицына вызвана тем, что в ряде лингвистических исследований стиля писателя смешиваются различные категории новых слов, на базе которых осуществляется развитие языка, а о точном их значении носитель языка может догадаться только на интуитивном уровне.

Так, в середине 60-х годов XX в. лингвистами обращается внимание на уникальную работу А. И. Солженицына над словом и указывается, что язык его произведений на первый взгляд отличается простотой, но это выверенная простота, которая «действительно может быть только результатом сложности - неизбежной сложности писательского труда, если этот труд честен, смел и свободен» [4, с. 31]. По существующему мнению, именно в повести «Один день Ивана Денисовича» это новаторство, вылившееся в систему индивидуального авторского словообразования и словоупотребления, привело к формированию уникального в языковом отношении лексического пласта, в наибольшей мере отражающего весьма неординарные моменты в понимании русской действительности. Например, обратимся к «восстановленной» лексеме деревянистый (в деревянистых ботинках). В менталитете русского человека данная единица имеет следующее значение: «...состоящий частично из деревянных, древесных волокон, древесины» [7, с. 430]. В повести «Один день Ивана Денисовича» писатель в опоре на текст и ассоциативные ресурсы текстовых единиц моделирует авторское понимание слова деревянистый. В данном случае ассоциирование может осуществляться в двух направлениях: схожий с чем-то деревянным по своему составу либо идентичный по качеству. В первом случае в тексте подобная ассоциация не наблюдается, ср.: Сосед сидел с поджатыми ногами на кровати, а я ходил, ходил медленно, сколько было длины, в чужих деревянистых ботинках... Идентичность по качеству (т.е. грубый, тяжелый, неудобный) четко прослеживается: в тексте А. И. Солженицын указывает, что герою трудно двигаться. Кроме того, данная семантика подтверждается контекстуально с помощью лексемы чужой (не подходящий по размеру, а следовательно, неудобный).

В середине 70-х годов XX в. в результате проведения серьезного лингвистического анализа лексики писателя лингвисты приходят к выводу, что А. И. Солженицын в текстах своих произведений не отказывается от заимствований полностью, стараясь все-таки не злоупотреблять ими. Однако среди так называемых «восстановленных» лексем заимствований практически нет [11]. По мнению лингвистов, А. И. Солженицын, используя данный прием в художественной речи, пытается сохранить определенный «лексический баланс», что дает возможность сохранить колорит русской лексики, передать специфику восприятия мира русским человеком, показать особенности менталитета русскоговорящих людей. Так, в рассказе «Пасхальный крестный ход» изобилуют слова с религиозной символикой (хоругвь, притвор, капище и др.), которые в советское время использовались писателями крайне ограниченно и в тех случаях, когда требовалось негативно описать факт из православной жизни человека. Используя данный пласт научных факторов в методических целях, мы можем утверждать, что овладение студентами-иностранцами «восстановленными» лексемами в полной мере погружает обучающегося в русские культурные особенности, в русский менталитет.

«Восстановленные» лексемы не существуют отдельно, а вовлекаются в ткань текста произведения, где контекстное окружение лексемы, согласно лингвистическим данным, способствует текстовой трансформации 
слова. Данное явление моделирования текстовых единиц в художественной речи приобретает статус авторского стиля и характеризуется писательским содержанием, раскрывающим авторское видение и интерпретацию действий, происходящих в окружающем пространстве [18; 21; 22]. Естественно, что видение и интерпретация происходящего А. И. Солженицыным будут осуществляться через тот формат понимания мира, который свойственен человеку, говорящему на русском языке. Например, в рассказе «Крохотки» знакомство с «восстановленной» лексемой бесплотность, определяемой в менталитете русского человека как «бестелесность; отсутствие плоти, тела, неимение плоти, состояние бесплотного существа», для студентов-иностранцев будет сопряжено с трудностями в плане лексической интерпретации и возможностей повседневного употребления.

Доказано, что А. И. Солженицын разработал принципы языковой реформы, направленной на обогащение современного русского языка и связанной с возвращением в повседневный обиход утраченных понятий и лексем, их называющих [19; 23; 25]. Писатель отказывается от нивелировки говоров в текстах своих произведений. Именно данный процесс, по его мнению, и приводит к деформации говоров, сводя их к псевдолитературному языку [19, с. 113]. Так, в рассказе «Матренин двор» встречаем диалектные слова молонья (молния), желадный (желанный), лопотно (хлопотно) и др. (из рязанских говоров), что сопряжено с местом описываемых в нем событий - в рязанской глубинке [8]. Осознанный отказ А. И. Солженицына от «обезличивания» диалектных слов в текстах своих произведений способствует сохранению самобытности и реалистичности описываемых событий, сопряженных с конкретным местом в России, бытом и нравами жителей. Данная этимологическая целостность поможет студенту-иностранцу сформировать целостное впечатление о национальных особенностях культуры русского человека.

\section{Практический аспект исследования}

Учитывая данные в области лингвистических исследований языка А. И. Солженицына относительно «восстановленных» лексем, мы имеем возможность предложить примеры приемов обучения, направленных не только на понимание студентами-иностранцами значения «восстановленных» лексем, но и способствующих проникновению в то ментальное восприятие мира, действий и событий, которое закреплено за носителем русского языка. Следует заметить, что приемы обучения предполагают прочтение студентами-иностранцами таких произведений А. И. Солженицына, как «В круге первом», «Матренин двор», «Один день из жизни Ивана Денисовича», «Архипелаг ГУЛАГ». Предложенные нами приемы обучения нацелены на работу с толковыми словарями русского языка, способствующими более детальной концептуализации заданной русским языком действительности в сознании неносителя русского языка, т.е. в сознании студента-иностранца.

\section{Пример 1}

- Из фрагмента текста «Несмотря на ужасающее невежество и беспонятность Спиридона Егорова в отношении высших порождений человеческого духа и общества - отличались равномерной трезвостью его действия и решения» выделите слово, которое не соответствует нормам русского языка (беспонятность) («В круге первом»).

- Постарайтесь выделить корень в слове беспонятность.

- К какой части речи относится слово беспонятность?

- Найдите слово беспонятность в толковом словаре и ознакомьтесь с семантикой данного слова (если такое слово присутствует в толковом словаре).

- Какое значение передает слово беспонятность? (тупоумие)

- Подберите синонимы к слову беспонятность (тупость, бестолковость, непонимание).

- Какое словесное окружение дополняет и расшифровывает слово беспонятность? (невежество)

- Какой образ дворника Спиридона Егорова возникает в сознании читателя? (некультурный человек)

- Какие слова дополняют образ дворника? (его действия и решения отличаются равномерной трезвостью)

- Какое восприятие человека, работающего дворником, возникает в сознании читателя? (дворник это работа для некультурных людей, но человек, выполняющий эту работу, может обладать достаточно развитым интеллектом)

\section{Пример 2}

- Из фрагмента текста «И как сидел, грелся в сером халате, уже наотмашь, - сам неподвижный и формы обломистой, как этот серый камень» выделите слово, значение которого является не полностью понятным (обломистой) («Раковый корпус»).

- К какой части речи относится слово? (прилагательное) Дайте начальную форму прилагательного (обломистый).

- Найдите слово обломистый в толковом словаре и ознакомьтесь с семантикой данного слова (если такое слово присутствует в толковом словаре).

- Подберите синонимы к прилагательному обломистый (обрывистый, крутой, отвесный).

- В каком контексте А. И. Солженицын употребляет прилагательное обломистый? (при характеристике главного героя Олега Костоглотова - бывшего зека, больного раком и перенесшего много испытаний не только находясь в заключении, но и при лечении неизлечимой болезни) 
- Какое значение пытался вложить А. И. Солженицын в слово обломистый, когда употребил данное слово при описании Костоглотова? (в данном контексте «обломистый» означает не крутой и отвесный, но очень прочный, угловатый; выдержавщий много испытаний)

- Какой образ отдельно взятого русского человека на примере Костоглотова показал А. И. Солженицын? (внешне похожий на камень и равнодушный ко всему человек, но с тяжелыми душевными переживаниями относительно своего заключения и неизлечимой болезни, которые он скрывает от внешнего мира, т.е. образ замкнутого русского человека с сильным характером)

\section{Пример 3}

- Во фрагменте текста «В это страшное время, когда в смятенном одиночестве сжигались дорогие письма и дневники, когда каждая пожелтевшая бумажка в семейном шкафу вдруг расцвела огненным папоротником гибели и сама порывалась кинуться в печь, какое мужество требовалось, чтобы тысячи и тысячи ночей не сжечь, сберечь архивы осужденных (как Флоренского) или заведомо упречных (как философа Федорова)!» выделите лексему, которая является незнакомой (упречных) («В круге первом»).

- Выделите корень слова и подберите однокоренные слова к слову упречный (упрек, упрекать и т.д.).

- Какое значение приобретет данное слово, если к нему прибавить приставку БЕЗ? (безупречных; безупречный: не заслуживающий ни в чем упрека, не имеющий недостатков) Является ли слово безупречный знакомым в сравнении со словом упречный?

- Найдите слово упречный в толковом словаре и ознакомьтесь с семантикой данного слова (если такое слово присутствует в толковом словаре) (укорительный, укоризненный).

- Какое значение передает слово упречный в контексте произведения А. И. Солженицына? («упречный» в тексте А. И. Солженицына наделяется обобщенным значением, включающим общеизвестное толкование (укорительный) и собственно авторское - обреченный, заведомо опасный)

- Какое лексическое окружение слова упречный способствует осознанию семантики данного слова? (когда каждая пожелтевшая бумажка в семейном шкафу вдруг расцвела огненным папоротником гибели и сама порывалась кинуться в печь, какое мужество требовалось, чтобы тысячи и тысячи ночей не сжечь, сберечь архивы осужденных или заведомо упречных)

- Какие ассоциации вызывает слово упречный в контексте данного фрагмента? (нагнетание чувства опасности)

- Какое восприятие исторической действительности в связи со словом упречный возникает в сознании читателя? (страх перед сталинскими репрессиями; осознание необходимости постоянно что-то скрывать и прятать, чтобы не прослыть врагом народа; постоянные отречения от отца и матери как от врагов народа, чтобы спасти собственную жизнь)

\section{Пример 4}

- Во фрагменте текста «Девки в цветных платочках и спортивных брюках (ну, и в юбках есть) голосистые, ходят по трое, по пятеро, то толкнутся в церковь, но густо там в притворе, с вечера раннего старухи места занимали, девчонки с ними перетявкнутся и наружу; но кружат по церковному двору, выкрикивают развязно, кличутся издали и разглядывают зеленые, розовые и белые огоньки, зажженные у внешних настенных икон и у могил архиереев и протопресвитеров» найдите лексему (существительное), которая является незнакомой (в притворе) («Матренин двор»).

- В каком падеже стоит существительное в тексте (предложный падеж)? Дайте форму именительного падежа для данного существительного (притвор).

- Найдите слово притвор в толковом словаре и ознакомьтесь с семантикой данного слова (пристройка перед входом в храм).

- C чем ассоциируется слово притвор в современном русском языке (дверь с притвором)?

- В каком контексте А. И. Солженицын употребляет существительное притвор? (в контексте описания церковной службы)

- Какое значение пытался вложить А. И. Солженицын в слово притвор согласно контекстному расположению слова? (притвор - коридорное помещение в храме)

- Какой образ церкви показан А. И. Солженицыным? (церковь - многолюдное место, где люди-прихожане могут быть одеты совершенно по-разному, особенно молодые представительницы женского пола (одеты в брюки, что не соответствует церковным устоям); шумное место, куда старухи приходят заранее, чтобы яснее увидеть крестный ход; крестный ход, в свою очередь, является значимым событием для русского человека, несмотря на доминирующие атеистические взгляды в стране)

\section{Заключение}

Таким образом, в ходе нашего лингводидактического исследования мы можем прийти к следующим выводам.

С позиции лингвистического анализа развитие языка для А. И. Солженицына - полифункциональный процесс, ориентированный на пополнение и трансформацию языковых уровней за счет вхождения в их состав когда-то утерянных, но восстановленных элементов, зачастую с нарушением существующих законов языка. 
А. И. Солженицын обращает особое внимание на внутреннюю систему неязыковых (ассоциативных, содержательно-смысловых и пр.) ресурсов и текстовых возможностей лексем. Писатель опровергает сложившееся в лингвистике мнение, что язык для своего развития использует уже существующие модели или организует на основе словообразовательных средств новые, таким образом, занимая пассивное положение. «Восстановленные» лексемы, используемые А. И. Солженицыным в «живых» текстах, многогранно отражают специфику восприятия русским человеком окружающего мира через интерпретацию явлений окружающей действительности героями произведений писателя. Трансформация лексических единиц в произведениях А. И. Солженицына формируется по определенной модели, неизвестной или знакомой носителям языка, и обладает высоким уровнем экспрессивности, отражая менталитет нации. Обращение студентов-иностранцев в процессе изучения русского языка на продвинутом уровне к специфике выражения «восстановленных» лексем способствует глубокому осознанию менталитета русского народа, сокращает дистанцию в понимании особенностей менталитета русскоговорящего человека. Именно в художественных и публицистических сочинениях А. И. Солженицына «восстановленные» лексемы получают возможность участвовать не только в расширении границ произведений автора, но и самого языка, отражающего ментальные особенности его носителей. Включение в процесс обучения студентов-иностранцев русскому языку на продвинутом уровне текстов А. И. Солженицына с целью познания особенностей менталитета русского народа считаем вполне обоснованным.

С позиции методики обучения студентов русскому языку как иностранному «восстановленные» лексемы, присутствующие в произведениях А. И. Солженицына, дают возможность преподавателю предложить такие приемы обучения, которые способствуют не только шлифовке фонетических, лексических, грамматических навыков обучающихся и обогащению словарного состава, но и нацелены на постижение студентамииностранцами менталитета русского народа, расширение кругозора, осуществление полноценной русскоязычной коммуникации с полным пониманием не только смысла высказывания, но и особенностей восприятия русскими людьми окружающей действительности. В сознании неносителя русского языка происходят особым образом организованные когнитивные процессы, дающие возможность в полной мере осознать особенность менталитета русского народа не только на примере «восстановленных» лексем, но и на примере контекстуального окружения подобных текстовых единиц. Единицы конкретного художественного текста в сознании студента-иностранца франкируют определенную «восстановленную» лексему, природа которой уже актуализирована, и вовлекают ее в процесс «пошагового» толкования заложенного смыла, тем самым упрощая процесс постижения культурных ценностей и особенностей менталитета русскоговорящих людей.

\section{Список источников}

1. Александрова О. И. Неологизмы и окказионализмы // Вопросы русского современного словообразования, лексики и стилистики. Куйбышев, 1974. С. 3-9.

2. Брагина А. А. Неологизмы в русском языке. М.: Просвещение, 1973. 224 с.

3. Брагина А. А. Чужое - свое (от заимствования к словотворчеству) // Грамматика и норма / отв. ред. Л. И. Скворцов. М.: Наука, 1977. С. 250-265.

4. Винокур Г. О. О языке художественной литературы. М.: Высш. шк., 1991. 448 с.

5. Гончарова Н. А. Истоки формирования концепта «патриотизм» в сознании подрастающего поколения // Идея патриотизма в системе воспитания подрастающего поколения: сб. материалов Всерос. науч.-практ. конф. (Краснодарский край, с. Сукко; Всероссийский детский центр «Смена», 16-18 апреля 2019 г.). Пенза: Изд-во ПГУ, 2019. С. 101-106.

6. Гончарова Н. А. Логический подход к формированию филологической компетенции студентов магистратуры педагогических вузов (на материале национальных вариантов английского языка): дисс. ... д. пед. н. Мичуринск, 2011. 489 с.

7. Даль В. И. Толковый словарь живого великорусского языка: в 4-х т. М.: Рус. яз. - Медиа, 2003. Т. 1. 699 с.

8. Даль В. И. Толковый словарь живого великорусского языка: в 4-х т. М.: Рус. яз. - Медиа, 2003. Т. 2. 799 с.

9. Дишкант Е. В. Педагогические аспекты изучения русской национальной культуры иностранными студентами // Вестник Северо-Восточного федерального университета им. М. К. Аммосова. Серия «Педагогика. Психология. Философия». 2018. № 1 (09). С. 5-14.

10. Жаркова Е. Х., Назарцева Е. А. Трудности освоения иностранными учащимися эмоционально-оценочного переосмысления в тексте // Преподавание русского языка как иностранного в вузе: традиции, новации и перспективы: сборник по материалам IV Международной научно-методической конференции (25-26 февраля 2016 г.). М., 2016. С. 195-201.

11. Карпович В. Исследование новообразований и далевских слов у Солженицына // Грани. 1974. № 94. С. $236-266$.

12. Кретинина Г. В. Методика обучения студентов филологических факультетов иноязычной спонтанной речи (английский язык как дополнительная специальность): автореф. дисс.. к. пед. н. Тамбов, 2002. 20 с.

13. Крючкова Л. С., Мощинская Н. В. Практическая методика обучения русскому языку как иностранному: учебное пособие для начинающего преподавателя, для студентов-филологов и лингвистов, специализирующихся по русскому языку как иностранному. М.: Флинта; Наука, 2009. 480 с.

14. Лыков А. Г. Окказионализм и язык. Норма // Грамматика и норма / отв. ред. Л. И. Скворцов. М.: Наука, 1977. C. 62-83. 
15. Лыков А. Г. Современная русская лексикология. М.: Высш. шк., 1976. 119 с.

16. Лю Ц. Фактор культуры в преподавании русского языка как иностранного // Образование и воспитание. 2015. № 5. С. 65-68.

17. Перевозникова А. К. Практика профессионально-ориентированного обучения иностранцев русскому языку (на материале учебного пособия «Русский язык для дипломатов») // Преподавание русского языка как иностранного в вузе: традиции, новации и перспективы: сборник по материалам IV Международной научнометодической конференции (25-26 февраля 2016 г.). М., 2016. С. 466-473.

18. Пискунова С. В. Тайны поэтической речи (грамматическая форма и семантика текста): монография. Тамбов: Изд-во ТГУ, 2002. 408 с.

19. Подольская Н. В. Дар русскому языку // Русская речь. 1992. № 1. С. 112-116.

20. Позднякова А. А. Русский язык как иностранный: в 2-х ч. М.: Юрайт, 2014. Ч. 1. Учебник и практикум. 417 с.

21. Руделёв В. Г. Принципы сегментации поэтической речи: в 6-ти т. Тамбов: Изд-во Тамб. гос. техн. ун-та, 2002. Т. 6. 178 с.

22. Русский словарь языкового расширения / сост. А. И. Солженицын. Изд-е 3-е. М.: Русский путь, 2000.280 с.

23. Семенова Г. П. Чтобы слова не утекли, как вода: о языке произведений А. Солженицына // Русская речь. 1996. № 3. С. 19-28.

24. Сибгатуллина В. Ф., Фахрутдинова М. Т. К вопросу об экстралингвистических факторах, влияющих на изучение русского языка как иностранного // Преподавание русского языка как иностранного в вузе: традиции, новации и перспективы: сборник по материалам IV Международной научно-методической конференции (25-26 февраля 2016 г.). М., 2016. С. 550-556.

25. Спиваковский П. Е. Лексическое расширение в эпопее А. И. Солженицына «Красное колесо» // Реферативный журнал. Социальные и гуманитарные науки. Отечественная литература. Сер. 6. Языкознание. 1994. № 4. С. 54-64.

26. Ханпира Э. Окказиональные элементы в современной речи // Стилистические исследования (на материале современного русского языка): сб. статей / под ред. В. Д. Левина. М.: Моск. гос. ун-т, 1972. С. 245-316.

27. Чуксина О. В., Кретинина Г. В., Гончарова Н. А. Обучение англоязычному диалогическому общению: социокультурный аспект // Высшее образование в России. 2007. № 4. С. 160-162.

28. Швецова В. М. Лексико-ассоциативные ресурсы текстовых единиц // Вестник Волгоградского государственного университета. Серия 2. Языкознание. 2010. № 1 (11). С. 205-211.

29. Швецова В. М. Принципы взаимодействия компонентов внутриполевого пространства голографической единицы в процессе развития текстовой семантики // Вестник Мичуринского государственного аграрного университета. 2013. № 1. С. 178-180.

30. Швецова В. М. Принципы семантического развития голографических единиц в смысловом пространстве художественного текста // Вестник Пятигорского государственного лингвистического университета. 2010. № 2. С. $123-126$.

\section{Информация об авторах | Author information}

RU Гончарова Наталья Александровна ${ }^{1}$, д. пед. н.

Швецова Виктория Михайловна ${ }^{2}$, д. филол. н., доц.

1,2 Мичуринский государственный аграрный университет

EN Goncharova Natalya Alexandrovna ${ }^{1}$, Dr

Shvetsova Victoria Mikhailovna ${ }^{2}$, Dr

${ }^{1,2}$ Michurinsk State Agrarian University

${ }^{1}$ nata-alexa@mail.ru, 2vmsh72@yandex.ru

\section{Информация о статье | About this article}

Дата поступления рукописи (received): 28.05.2020; опубликовано (published): 31.08.2020.

Ключевые слова (keywords): особенности менталитета русского народа; обучение русскому языку; «восстановленные» лексемы; авторский стиль А. И. Солженицына; авторские приемы обучения студентов-иностранцев; specificity of Russian mentality; teaching Russian as a foreign language; “revived” lexemes; A. I. Solzhenitsyn's individual style; author's techniques to teach foreign students. 